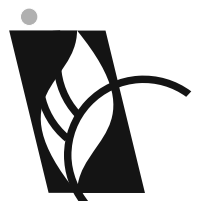

J O U R N A L

$\mathrm{O} F \bullet \mathrm{B} \mathrm{A} \mathrm{L} \mathrm{T} \mathrm{I} \mathrm{C}$

$S$ C I E N C E

E DUCATION

\section{ISSN 1648-3898}

Abstract. Given the worldwide interest in improving student academic attainment, it is important to the examine the variables impacting college students' achievement.

This research aimed to predict student achievement in an undergraduate level Scientific Research Method Course (SRMC) offered by Celal Bayar University, Turkey.

This quantitative research adopted a descriptive correlation survey design. 198

sophomore college students were the participants of the study. Multiple linear regression analysis was used to examine how independent variables such as attitudes, competence in teaching methods, length of studying time, gender predict student achievement in SRMC. The findings showed that selected predictors accounted for $33.4 \%$ of students' academic achievement in SRMC. Specifically, 23\% of this variance were explained by the total study hours; $9.4 \%$ of it originated from

students' attitudes toward the lesson; and $2 \%$ of it originated from the students perceptions of the necessity and importance of the course. Further, these findings are positioned with respect to the previous

research on predicting college student achievement.

Key words: achievement, attitude, college student, science course, study time.

Abdurrahman Ilgan Celal Bayar University, Turkey

\section{PREDICTING CDLLEGE STUDENT ACHIEVEMENT IN SCIENCE CDURSES}

\section{Abdurrahman Ilgan}

\section{Introduction}

Student learning in higher education has been the subject of intense research for more than two decades, with major findings of this inquiry summarized in several informative monographs (Biggs, 1999; Dart \& Boulton-Lewis, 1998; Marton et al., 1997; Prosser \& Trigwell, 1999; Watkins \& Biggs, 1996; as cited in Zeegers, 2004). One of the key findings from this large body of research is that learning is a complex human activity that cannot be easily conceptualized by means of a simple model. The factors that can impact students' success in higher education are manifold, but they are sometimes categorized as being either personality factors (e.g., age, prior experiences, learning styles) or contextual factors (e.g., teaching and learning activities, assessment procedures). Numerous studies have attempted to correlate learning outcomes in higher education with individual contributing factors; however, few studies have attempted to elucidate the inter-relationship between contributing factors in order to develop a casual model of achievement (Zeegers, 2004). This research contributes to the discourse surrounding student learning in higher education institutions by focusing on the Turkish context.

Academic achievement is the major aim of secondary and postsecondary education systems. There are numerous factors in the college environment that influence Grade Point Average (GPA) and performance across a wide range of academic subjects such as prior knowledge of subject, skills, and cognitive abilities (Plant, Ericsson, Hill \& Asberg, 2004). Research suggests that major factors in academic achievement are parents (family casual factors), teachers (academic casual factors), and other students (personal casual factors) (Diaz, 2003).

Given the increasing importance of science and mathematics in the modern world, there is considerable interest in such courses offered at the college-level; specifically in the predictors of student achievement. Student achievement in the introductory college level science courses is important. Because little is known about the factors that predict college science achievement (Gustafson \& 
Balke, 1993; House, 1996; Lawson, 1983), this research contributes to this subject that requires further examination.

As a variable that affects achievement, attitudes represent an individual's degree of positive or negative views (or likes or dislikes) of a particular person, place, thing, or event (attitude objects). These views are made up of clusters of personal beliefs about the attitude object that are acquired mainly through personal experiences (Matthew et al, 2011). Attitudes are defined as the overall positive or negative evaluation of the behavior. In general, the more favorable the attitude toward the behavior is, the stronger is the individual's intention to perform it (Lipnevich, MacCann, Krumm, Burrus, \& Roberts, 2011). Furthermore,

Student attitude towards study is a complex construct. Attitude is a fairly stable emotional tendency to respond consistently to some specific object, situation, person, or category of people. It has three components: cognitive core, affective values and behavioral action tendencies. The cognitive aspect of attitude consists of beliefs and ideas that a person has about the attitude object. The affective component includes the feelings of like and dislike toward any object, and the behavioral aspect consists of intentions to respond in a particular way toward the object. (Sarwar, Bashir, \& Alam, 2010, p.55).

Academic achievement and student's attitudes and study habits are closely related. It is necessary to improve student's study habits and attitudes to increase student's academic achievement (Aquino, 2001). A student's attitude is an important factor in learning science. Positive attitudes towards science can inspire students to pursue degrees in science and science-related careers (Carey \& Shevelson, 1988; Norwich \& Duncan, 1990). Literature provides evidence that attitude is an important motivator of behavior and positively affects the achievement of students (Hussain, 2006). The inspection of the attitudes that students exhibit toward science is very important since attitudes can influence student's educational achievement. These influences can reinforce higher or lower performance (Papanastasiou \& Papanastasiou, 2004). Researchers in science education (e.g., Hammer, 2000; Redish, 2003) have found that student classroom experience is shaped by a variety of student attitudes and beliefs. Some researchers (Ma \& Xu, 2004; Okpala, 2001; Sarwar, Bashir, \& Alam, 2010; Simonson \& Maushak, 1996) found a positive correlation between attitude and academic achievement. Research is also indicates that students' expectations are significant predictors of college science performance (House, 1996; Tai \& Sadler, 2001). Furthermore, significant correlations between students' mathematics attitudes and their score on mathematics achievement were reported (Klossterman, 1991). Benbow and Stanley (1982) found that talented students that held positive attitudes toward mathematics, science, and school were already high achievers.

While examining general attitudes toward school, Lupart, Cannon and Telfer (2004) found that female students have more positive attitudes than male students. The study of Lupart et. al reported that girls exhibited a better attitude toward learning for learning's sake than boys. In total, $73.6 \%$ of the females either agreed or strongly agreed that they do schoolwork because they like to learn new things, whereas only two-thirds (66.7\%) of the males responded in this way. A similar conclusion was reported by Marjoribanks (1987) who found that girls had significantly more positive affective school attitudes than boys.

Another variable related with academic achievement is the amount of time spent on studying. The total amount of study time that students report has been often examined as a potential predictor of school success. Bloom (1974, p. 682) asserted that "all learning, whether done in school or elsewhere, requires time". It is conventionally accepted that the more time students spend studying, the better grades they receive (Plant, Ericsson, Hill, \& Asberg, 2004). Maddox (1963, p.14; as cited in Beer \& Beer, 1992) asserted that study time and class attendance are important influences on success because "Failure to attend classes is one obvious cause of poor performance .... Those who frequently cut class were less likely to get high marks than those who were regular in their attendance". Lahmers and Zulauf (2000) found that the amount of time spent studying is also considered a key input, even though past studies have yielded mixed findings regarding its statistical significance. Capella, Wagner and Kusmierz (1982) reported a .46 Pearson correlation between GPA and study behavior. Britton 
and Tesser (1991) believed that good organization and goal setting (i.e., planning activities a week or more in advance) created a more focused approach to studying and more efficient monitoring of goal accomplishment. They found that self-management practices such as prioritizing tasks were predictive of college students GPAs. Consistent with Britton and Tesser (1991), Lahmers \& Zulauf's (2000) reported that both gender and time management were statistically related to GPA. The better are the students' time management skills, the higher are the students' GPAs. Plant et. al. (2004) found that students who indicated that they studied alone in an environment with less distractors, tended to perform better both in the current semester and cumulatively, and percentage of classes attended as a variable related with total amount of time was correlated with the participants' current and cumulative GPAs. It means that students who attended a higher percentage of their classes had higher GPAs, consistent with the findings of Schuman, Walsh, Olson, and Etheridge (1985). Hinrichsen (1972) found that the amount of effective study time (i.e., the number of uninterrupted minutes spent studying) predicted GPA. In addition, Allen, Lerner \& Hinrichsen, (1972) found that the number of interruptions that students reported during studying was negatively correlated with GPA. These findings suggest that studying environment is an important factor for high grade in college.

Pintrich and Garcia (1991) found that students who set goals, plan effectively and monitor goal progress are more likely to achieve higher on knowledge tests than students who fail to engage in these activities. Zimmerman (1994) suggested that time planning and management training helped students to better self-regulate their use of study time and contribute to improving their results. Consistently with the findings of Zimmerman (1994), Van Den Hurk (2006) found that students who are better time-planners and who have better self-monitoring skills are more efficient in allocating their individual study time, prepare more appropriately for tutorial group meetings, and score higher on cognitive tests.

Another variable that affects college students' achievement is gender. It is widely accepted that females score higher on average than males on test of verbal abilities and that males score higher on average than females on tests of mathematical ability (Halpern, 1996; Hyde, Fennema, \& Lamon, 1990; Stumpf, 1995). However, these differences are small. The vast majority of the primary research on gender differences has used small and unrepresentative samples, making it difficult to generalize findings to the well-defined national populations (Mattehews, Ponitz, \& Morrison, 2009). Nowell and Hedges (1998) found that gender differences in mean and variance are for the most part very small and have remained stable since 1960, with the possible exception of mean differences in mathematics and science. Even for the trends in science and mathematics that were statistically significant, the rate of change is extremely low and certainly not practically significant. Paglin and Rufolo (1990) suggested that quantitative ability (but not verbal ability) "accounts for the observed male-female differences in earning and occupational choices of recent college graduates" (p. 123). Murray-Harvey (1993) used path analysis to predict academic achievement of 423 education and nursing freshman students. The model explained $44 \%$ of the variance in achievement, with metacognitive capability being the best predictor of academic achievement $(\beta=.45)$ and a significant contribution from student gender, age, and approaches to learning.

\section{Research Focus}

This research aimed to predict student achievement in Scientific Research Method Course (SRMC) at an undergraduate level. The dependent variable was the final examination results of the course. Independent variables were: (1) Gender, (2) Length of studying time (in hours) to success the course during semester, (3) the importance and necessity of the course perceived by students as a continuous variable (requested from to participants to score the importance and necessity of the course from 0 to 100), (4) students' attitudes toward the scientific research method course, (5) students' attitudes towards the instructor of the course, (6) students' perceptions of competence in teaching methods used for the course. The review of the literature revealed numerous variables affecting academic achievement of students. Student, course characteristics, and teacher qualities are expected to predict study time and grades, and also moderate the study time-grade association (Olivares, 2002). 
In the present research, the variables selected as independent variables were directly related with teaching and/or classroom settings and instructor. Other independent variables were gender and the length of studying time as previous research suggests that they significantly impact academic achievement of college students. Family and sociocultural backgrounds of college students may affect their academic achievement. Kaya \& Büyükkasap (2005) and Akbayır (2003) reported that the majority of students enrolled in the college of education in Turkey come from low or middle class. Therefore, the study assumed that the students participating in this research have similar family and sociocultural backgrounds. For this reason, family and sociocultural backgrounds of students were not included in the model.

Another factor affecting academic achievement is intelligence. Students in the sample for this study were studying in the same department, at the same level, and have enrolled in college after passing a centralized, high stake, validated and reliable examination. Therefore, the students who participated in this research were similar in terms of intelligence and academic achievement. That is why family and sociocultural backgrounds and intelligence were not included as independent variables. However, the variables selected as independent variables for this research, could be viewed as a limitation of this study.

The main hypothesis of the research is: gender, length of studying time, the importance and necessity of the course, student attitude toward the course, students' attitudes towards the instructor, and the competence in teaching methods will predict the student achievement at a statistically significant level.

\section{Methodology of Research}

\section{General Background of Research}

The quantitative research method was used for his study. Quantitative research designs were divided by Creswell (2005) into two broad categories: intervention research and non-intervention research. The purpose of this non-intervention research was to analyze the relationships among variables without intervention or manipulation. The model of this research is a correlation design that does not require random selection of participants and does not manipulate variables or participants. Correlational designs are appropriate when the researcher is interested in determining to what extent two or more statistically measurable variables covary (Vogt, 2005). Fraenkel and Wallen (2009) defined correlational research as a study that aims to determine the degree to which a relationship exists between two or more variables. Creswell (2005) described two categories of correlational designs: prediction and explanatory. Prediction correlational studies are appropriate once the relationship between variables has been established and a researcher is interested in further examining how one variable influences the others. So, it is possible to say that prediction correlation design is an appropriate choice for this research. The study goal was to predict student achievement by selected variables. In this study, the dependent variable is academic achievement of SRMC, whereas the independent (predictor) variables are (a) students' attitudes towards the course, (b) students' attitudes toward the lecturer, (c) students' perception of lecturer's competency in teaching methods, (d) the time spent to succeed in the course, and (e) students' perceptions of the necessity and importance of the level for the course.

\section{Study Sample}

The participants in this study were 198 sophomore college students (female $=136$, male=62) enrolled in SRMC taught by the researcher at the Department of Primary School Teaching at Celal Bayar University College of Education in the spring semester of 2012. All sophomore students $(\mathrm{N}=198)$ who enrolled in the SRMC taught by researcher were included in the sample of this research. In this study, "students' attitudes towards the course", "students' attitudes towards the instructor" and "students' perception of the instructor's competency in teaching methods" were used as independent 
variables related closely with the instructor who taught the course. Adding to the sample the students of a different instructor could have impacted the statistical results. Therefore, the students of the same class taught by a different instructor were not invited to participate in this research. The instrument was administered after the final examination; the participation was voluntary. The students were encouraged by the instructor to fill in the anonymous survey; the instructor offered clear explanation to the students that this survey will not affect their grade for SRMC in any way.

\section{Instruments and Procedures}

The research instruments aimed to collect the data about: (1) students' attitudes towards the course, (2) students' attitudes towards the instructor and (3) students' perceptions of the lecturer's competency in teaching methods. All the scales were Likert Type. Additional to these instruments, two more questions were asked addressing the (1) approximate total studying hours during the semester to succeed in the SRMC and (2) the students' perceptions of the necessity and importance of the course for the teaching profession and their future life. The students were requested to give points from 0 to 100; 0 was not necessary and 100 denoted completely necessary.

The data collection tool was developed based on the related literature and was evaluated for content and face validity by the experts in the fields of university teaching and the measurementevaluation field. Both exploratory and confirmatory factor analyses were used in this study. Exploratory factor analysis (Schmitt, 2011) was conducted to examine the construct validity of each scale. Factor analysis is a technique used to identify or confirm a smaller number of factors or latent constructs from a large number of observed variables (or items) (Worthington \& Whittaker, 2006). Factor loadings greater than 0.60 are considered high, and above 0.30 are considered moderately high (Kline, 2000). Principal Component Analysis (PCA) was used as an extraction method. PCA is one of the most commonly known and applied extraction methods (Worthington \& Whittaker, 2006). Worthington and Whittaker (2006) suggest to use Barlett's test and KMO to examine the adequacy of sample. Tabachnic and Fidell (2001) suggest that values of 0.60 and higher KMO are required for good factor analysis. Alpha coefficient and item-total correlation were used to test instrument reliability.

Researchers typically use confirmatory factor analysis (CFA) after an instrument has already been assessed using exploratory factor analysis (EFA), and they want to know if the factor structure produced by EFA fits the data from a new sample. Worthington and Whittaker (2006) suggest that rather than conducting CFA that would ultimately need to be followed by a second CFA, the most logical approach would be to conduct an EFA followed by a CFA in all cases. Thus, when developing new scales, researchers should conduct an EFA first, followed by CFA. This research used EFA followed by CFA to examine the validity of the scales used. The details about the reliability and validity of the instruments are explained below.

\section{Students' Attitudes towards the Course Scale (SAtCS)}

This scale was developed by the researcher for the purposes of this study. It is a 5 point Likert Type scale with response options: (1) strongly disagree, (2) disagree, (3) moderately agree, (4) agree, and (5) strongly agree. SAtCS scale was initially composed of 19 items, 12 of them were positive and 7 of them were negative. Due to the factor loadings of 3 items being below 0.40 and replacing in different factor 3 items, a total of 6 items were deleted. Kaiser-Meyer-Olkin (KMO) test value was .929 and the Barlett's test $(<0.000)$ was significant for SAtCS. According to this result, it can be said that the data were factorable. The factor loadings of SAtCS (including 13 items, 10 positive and 3 negative) values ranged from 0.544 to 0.794 . Thus, the items had high factor loadings. There was a single factor that explained $49.2 \%$ of the variance. Item-total correlations of SAtCS values ranged from 0.485 to 0.737 . Therefore, the item-total correlations were in moderate level. Cronbach's Alpha reliability coefficient for the SAtCS was 0.911. 
Example items for SAtCS:

I prefer to get different course instead of SRMC.* ${ }^{*}=$ Negative item).

SRCM covers important and valuable topics.

SRCM will contribute to my working life.

\section{Students' Attitudes towards the Instructor Scale (SAtIS)}

The scale was developed by the researcher. It is 5 point Likert Type scale and the response options were (1) strongly disagree, (2) disagree, (3) moderately agree, (4) agree, and (5) strongly agree. SAtIS scale was initially composed of 12 items. All SAtIS items were positive. Due to 3 items having below 0.40 factor loadings, and replacing in different factor 1 item, a total of 4 items were not included in the analysis. KMO test value was 0.849 and the Barlett's test $(<0.000)$ was significant for SAtIS. Therefore, the data was factorable. The factor loadings values of SAtIS (including 8 positive items) ranged from 0.606 to 0.771 . Thus, the items had high factor loadings. There was a single factor that explained $49.5 \%$ of the variance. Item-total correlations of SAtIS values ranged from 0.526 to 0.683 showing that item-total correlations were moderate; the Cronbach's Alpha reliability coefficient for the SAtIS was 0.868 .

Example items for SAtIS:

The instructor had a good impression on me.

I want to take one more course from this instructor.

The instructor is open to criticism.

\section{Competency in the Teaching Methods Scale (CTMS)}

The students' perceptions of the instructor's competency in teaching methods scale was developed by the researcher for this study. It was a 5 point Likert Type scale and the response options were (1) strongly disagree, (2) disagree, (3) moderately agree, (4) agree, and (5) strongly agree. CTMS was initially composed of 14 items. Due to an item factor loading below 0.40 one item was deleted. $\mathrm{KMO}$ test value was .887 and the Barlett's test $(<0.000)$ was significant for the CTMS. According to this result, it can be said that the data is factorable. The factor loadings of CTMS (including 13 items) values ranged from 0.553 to 0.798 . Thus, the items had high factor loadings. There was a single factor explaining $43.06 \%$ of the variance. Item-total correlations of the CTMS values ranged from 0.464 to 0.721 . It is possible to say that item-total correlations were moderate. Cronbach's Alpha reliability coefficient for the CTMS was 0.884 .

Example items for CTMS:

The lecturer used his voice effectively

The course was fulfilled effectively

The student was motivated for the research

The course topics were demonstrated by examples

Results including incremental, absolute, and predictive fit index for confirmatory factor analysis of the scales used in this research are presented in the Table 1.

According to Kline (2005), a minimum collection of these types of fit indices to report would consist of (a) the chi-square test statistic with corresponding degrees of freedom and level of significance, (b) the RMSEA with its corresponding 90\% confidence interval, (c) the Comparative Fit Index $(\mathrm{CFI})$, and (d) the SRMR. 
Table 1. Results of confirmatory factor analysis of the scales.

\begin{tabular}{lcc}
\hline \multicolumn{1}{c}{ Incremental, Absolute and Predictive Fit Index } & \multicolumn{2}{c}{ Scales } \\
\cline { 2 - 3 } & & SAtIS \\
\hline Chi-squarre / df tario & 3,46 & 3,2 \\
Root Mean-Square Error of Approximation (RMSEA) & 2,75 & 0.11 \\
Root Mean Square Residual (RMR) & 0.095 & 0.059 \\
Goodness-of-Fit Index (GFI) & 0.056 & 0.91 \\
Adjusted Goodness-of-Fit Index (AGFI) & 0.88 & 0.84 \\
Nonnormed Fit Index (NNFI) & 0.83 & 0.07 \\
Comparative Fit Index (CFI) & 0.96 & 0.93 \\
\hline
\end{tabular}

Researchers (Beauducel \&Wittmann, 2005; Marsh, Hau, \&Wen, 2004) have commonly interpreted the range of different cutoff values for fit indices suggested in the structural equation modeling literature: (a) acceptable fit: root-mean-square error of approximation (RMSEA) $\leq 0.08$, standardized root-mean-square residual $(S R M R) \leq 0.09$, and comparative fit index $(C F I) \approx 0.90$; (b) good fit: RMSEA $\leq 0.05$ (or $90 \%$ confidence interval $[\mathrm{Cl}]$ of the RMSEA including 0.05 ), SRMR $\leq 0.09$, and CFI $\geq 0.95$ Results in the Table 1 show that SAtCS, SAtIS and CTMMS scales have acceptable incremental, absolute and predictive fit indexes.

\section{Data Analysis}

The data gathered by SAtCS, SAtIS, CTMS scales have been analyzed by the SPSS (Version 20). In order to see how accurately the selected independent variables could predict student academic achievement in SRMC, Multiple Linear Regression analysis was used. For the gender variable, "female" was coded as 1, and "male" was coded as 0 . The dependent variable was student achievement whereas the independent (predictor) variables were students' attitudes towards the course, and toward the lecturers, students' perceptions of the competency in teaching methods, the total amount of time (hours) spent to succeed in the course, students' perceptions of the importance and necessity of the course. The scales were administered after the final examination of SRMC. The index of kurtosis and skewness for SAtCS and SAtIS scales was between +1 and -1 , which is considered excellent. The skewness index of CTMS scale was -0.86 and kurtosis index of CTMS scale was 1.66 , which is considered acceptable (George \& Mallery, 2001). The results for this indicate that parametric statistic procedures to analyze the data were appropriate.

\section{Results of Research}

Basic descriptive statistics about the data collected for this research are summarized in Table 2.

Table 2. Descriptive statistic for key variables.

\begin{tabular}{|c|c|c|c|c|c|}
\hline Name of the Variables & $\mathrm{n}$ & $\begin{array}{l}\text { Minimum } \\
\text { Score }\end{array}$ & $\begin{array}{l}\text { Maximum } \\
\text { Score }\end{array}$ & $\overline{\mathrm{X}}$ & SD \\
\hline Academic Achievement for SRMC & 198 & 31 & 100 & 64.70 & 12,66 \\
\hline Total Studying Hours (TSH) & 198 & 1 & 60 & 15.73 & 11.72 \\
\hline The necessity and Importance of the Course (NIC) & 198 & 20 & 100 & 71.78 & 14.72 \\
\hline Attitudes towards the Course (ATC) & 198 & 26 & 65 & 44.31 & 8.53 \\
\hline Attitudes towards the Instructor (ATI) & 198 & 18 & 45 & 36.77 & 5.14 \\
\hline Competency in Teaching Methods (CTM) & 198 & 20 & 65 & 50.72 & 7.34 \\
\hline
\end{tabular}


As it can be seen from Table 2, academic achievement score and the perception of the necessity and importance of the course are in moderate level whereas total studying hours during semester to succeed SRMC does not seem adequate. It seems that undergraduate students in this sample did not study enough for SRMC. The average mean for attitude towards SRMC ( $X=44.31 / 13=3.41)$; competency in teaching methods $(X=50.72 / 13=3.9)$ and the attitudes towards the instructor $(X=36.77 / 9=4.09)$ were mostly positive.

Initial Multiple Linear Regression (MLR) analysis was used to predict SRMC achievement as a dependent variable while the independent variables were TSH, NIC, ATC, ATI, CTM and gender. The results of the regression analysis are presented in Table 3.

Table 3. The results of the multiple regression analysis predicting students achievement in SRMC.

\begin{tabular}{cccccccc}
\hline Variable & B & Std. Error & $\boldsymbol{\beta}$ & $\mathbf{t}$ & $\mathbf{p}$ & $\begin{array}{c}\text { Zero-order } \\
\mathbf{r}\end{array}$ & Partial $\mathbf{r}$ \\
\hline Constant & 33.163 & 6.549 & & 5.064 & 0.000 & & \\
TSH & 0.395 & 0.073 & 0.348 & 5.435 & 0.000 & 0.480 & 0.367 \\
NIC & 0.132 & 0.061 & 0.154 & 2.168 & 0.031 & 0.402 & 0.155 \\
ATC & 0.416 & 0.123 & 0.279 & 3.376 & 0.001 & 0.453 & 0.238 \\
ATI & 0.224 & 0.208 & 0.091 & 1.074 & 0.284 & 0.203 & 0.078 \\
CTM & -0.220 & 0.153 & -0.128 & -1.439 & 0.152 & 0.178 & -0.104 \\
Gender & 0.610 & 1.609 & 0.022 & 0.379 & 0.705 & 0.042 & 0.027 \\
\hline
\end{tabular}

As the results shown in Table 3 demonstrate, the $R=0.593, R^{2}=0.352$ and adjusted $R^{2}=0.331, p=$ 0.000. Results show that $33 \%$ of the total variance was accounted for by these variables. As it can be seen from the t test results, TSH, NIC, ATC are significant predictors of SRMC achievement while ATI, CTM and gender are not.

Stepwise Regression was then used to assess which independent variables made a significant contribution to predicting the academic achievement in SRMC. Through Stepwise Regression, it was possible to determine which variables significantly predicted academic achievement of SRMC as well as to determine how much each variable contributed to the total variance (see Table 4).

Table 4. Stepwise regression analysis for predictors of academic achievement in SRMC.

\begin{tabular}{ccccccccccc}
\hline Model & Predictors & $\mathbf{B}$ & $\begin{array}{c}\text { Std. } \\
\text { Error }\end{array}$ & $\boldsymbol{\beta}$ & $\mathbf{t}$ & $\mathbf{p}$ & $\mathbf{R}$ & $\mathbf{R}^{2}$ & $\begin{array}{c}\text { Adjusted } \\
\mathbf{R}^{2}\end{array}$ & $\begin{array}{c}\text { R sq. } \\
\text { Change }\end{array}$ \\
\hline \multirow{2}{*}{1} & Constant & 56.198 & 1.374 & & 40.91 & 0.000 & 0.480 & 0.230 & 0.226 & 0.230 \\
& TSH & 0.544 & 0.071 & 0.480 & 7.636 & 0.000 & & & & \\
\hline \multirow{2}{*}{2} & Constant & 36.614 & 3.989 & & 9.180 & 0.000 & & & & 0.094 \\
& TSH & 0.416 & 0.071 & 0.367 & 5.837 & 0.000 & 0.569 & 0.324 & 0.317 & \\
\hline & ATC & 0.487 & 0.094 & 0.326 & 5.189 & 0.000 & & & & \\
& Constant & 31.909 & 4.391 & & 7.268 & 0.000 & & & & 0.020 \\
& TSH & 0.388 & 0.071 & 0.342 & 5.438 & 0.000 & 0.587 & 0.344 & 0.334 & \\
& ATC & 0.370 & 0.104 & 0.248 & 3.541 & 0.000 & & & & \\
\hline
\end{tabular}

Note: The symbols used in the table are: TSH: Total study in hours, ATC: Attitudes towards the course; NIC: The necessity and importance of the course perceived by students. 
As it can be seen from Table 4, in the first model, TSH accounted for $22.6 \%$ of the total variance in academic achievement of SRMC $\left(R=0.48, R^{2}=0.23\right)$. In other words, Total Studying Hours (TSH) was the most effective independent variable to predict the academic achievement in SRMC. There is a moderate level positive correlation between TSH and academic achievement in SRMC $(r=0,48)$. This result shows that the more the students study, the more their academic achievement will increase.

In the second regression model (Table 4), ATC was added to TSH as the predictors of academic achievement of SRMC. Notably, the variance in academic achievement of SRMC rose from $22.3 \%$ to $31.7 \%\left(R=0.569, R^{2}=0.317\right)$. It means that ATC contributed to the overall variance an additional $9.4 \%$. In this model, the correlation coefficient between TSH and academic achievement in SRCM is positive and at a moderate level $(r=0.387)$, while the other independent variable ATC controlled this coefficient slightly decreasing correlation to $(r=0.345)$ and remaining at the same significance level. Another correlation coefficient in this model (between ATC and academic achievement in SRMC) is positive and at a moderate level $(r=0.349)$ while the other independent variable TSH controlled this coefficient slightly decreasing the correlation to $(r=0.306)$ and remaining at the same significance level. It means that if a student has a more positive attitude, he or she is likely to be a high achiever.

In the third, regression model (Table 4), NIC added to TSH and ATC as predictors of academic achievement of SRMC. As a result of the final model, the variance in academic achievement in SRMC increased from $31.7 \%$ to $33.4 \%\left(R=0.569, R^{2}=0.334\right)$. It means that NIC contributed to the overall variance an additional $2 \%$. In this model, the correlation coefficient between TSH and academic achievement of SRMC is positive and moderate $(r=0.365)$ while other independent variables ATC and NIC controlled this coefficient slightly decreasing the correlation to $(r=0.317)$ and remaining at the same significance level. Another correlation coefficient in this model between ATC and academic achievement of SRMC is positive and at a low level $(r=0.247)$ while other independent variables TSH and ATC controlled this coefficient slightly decreasing the correlation to $(r=0.206)$ and keeping the same significance level. The other correlation coefficient in this model between NIC and academic achievement in SRMC is positive and at a low level $(r=0.172)$ while other independent variables TSH and ATC controlled this coefficient slightly decreasing the correlation to $(r=0.141)$ and keeping the same significance level.

In the final model of predicting academic achievement in SRMC, the independent variables TSH, ATC, and NIH were statistically significant while ATI, CTM and gender were non-significant variables. The regression model was significant $\left[F_{(3,193)}=33.74 ; p<0.001\right]$ and yielded an adjusted $R^{2}$ of 0.334 . Multiple regression analyses accounted for $33.4 \%$ of academic achievement of SRMC. Thus, the regression equation for the academic achievement in SRMC is $=31.909$ Constant $+0.388 \mathrm{TSH}+0.370 \mathrm{ATC}+0.144 \mathrm{NIC}$.

\section{Discussion}

This research contributes to the discourse surrounding college students academic achievement initiated by the previous studies by examining different variables as predictors of student attainment. A research done by Fuligni (1997) to predict academic achievement of adolescents from immigrant families used these variables as independents: their perceptions of (1) their parents' aspirations for their future educational attainment and (2) the academic support they received from their peers, (3) their subject-specific values (math or English) and (4) their reports of the amount of time they spent studying each week. Each of these constructs evidenced significant bivariate relations with students' achievement. Students' grade level, gender, language use, and socio-economic status were also included in the analyses, but their results are not presented as they changed only slightly from the estimates presented earlier. Fuligni (1997) found that students'values and study time independently predicted their level of achievement consistent with result of this research.

Students may seek a satisfactory balance between study time and grades, whereby study time and grades may be influenced not only by the student characteristics (e.g., cognitive ability), but also by the course (e.g., difficulty) and teacher characteristics (e.g., grade inflation and teacher effectiveness) (Olivares, 2002). One of the important earlier studies conducted by Schuman et al. (1985) found a weak, yet reliable relationship between the reported study time and student grades. Similarly, Michaels and Miethe (1989) found a small $(r=0.18, p<0.01)$ relationship between reported study and GPA. Rau and 
Durand (2000) found that the amount of study hours was reliably related to GPA ( $r=.23, p<0.001)$ for an Illinois State University sample; the real benefits were only seen for students studying over 14 hours per week (about $25 \%$ of the ISU students in the sample). A similar finding was reported by Plant and at al. (2004) who found that study time emerged as a significant predictor of GPA, indicating that higher study time was associated with a higher GPA, $\left[F_{(1,74)}=5.94, p<0.02(b=0.24)\right]$. When considering cumulative GPA, the overall amount of study time only emerged as a significant predictor of performance when the quality of the study environment and scholastic aptitude at the college entry (SAT) were included in the regression equation. Thus, it appears that the amount of study time may only emerge as a reliable factor that determines performance when the quality of study time and the students' SAT scores are also taken into consideration (Plant et al., 2004). Hurk, Wolfhagen, Dolmans and Vleuten (1999) found that students who go beyond the learning issues and spend more time on the individual study also achieve better on the knowledge tests. Reynolds and Walberg (1992) found that instructional time was one of the greatest predictors of science achievement in grade 11 along with prior achievement, home environment, and exposure to mass media through reading.

The research by Fuligni and Stevenson (1995) conducted in three locations: Minneapolis (USA), Taipei (Taiwan) and Sendai (Japan) among students aged 16-17 (grade 11 students) found similar results in all three locations. The time spend on studying was positively related to the students' scores, while the times spent working, watching television, and being with friends were negatively related. When the researcher regressed on the students' mathematics scores, a moderate but highly significant percentage of variance was predicted by the various indices of time use in all three locations. The $\mathrm{R}^{2}$ for Minneapolis was 0.27 ; for Taipei, 0.26 ; and for Sendai, 0.20 , all ps were $<0.001$. The amount of time spent studying, as reflected in the significant betas, was related to scores on the mathematics tests in Sendai (0.23) and Taipei (0.18), but, surprisingly, not in Minneapolis (0.04). In the Turkish context, Ilgan and Kiranli (2008) found that the length of study time explained $15 \%$ of variance in academic achievement of college student in the university classroom management course.

The results of this research show that the total amount of study time to succeed in the course significantly predicted academic achievement of SRCM among college students consistent with related previous research results (Bachman \& Schulenberg, 1993; Fuligni and Stevenson, 1995; Fuligni, 1997; Schuman et al, 1985; Greenberg \& Steinberg, 1986; Hurk, Wolfhagen, Dolmans and Vleuten, 1999; Ilgan \& Kıranlı, 2008), Larson, 1983; Leone \& Richards, 1989; Michaels and Mieth, 1989; Plant et al., 2004; Rau and Durand, 2000), whereas other researchers interested in the relationship between the weekly amount of the reported study time and grade point average (GPA) for college students found weak or unreliable relationship (Beer \& Beer, 1992; Lahmers \& Zulauf, 2000; Schuman et al, 1985).

This research showed that students' attitudes towards the course served as a predictor of academic achievement of college students consistent with earlier research from other countries (Hammer, 2000; Hussain, 2006; Ma \& Xu, 2004; Okpala, 2001; Papanastasiou \& Papanastasiou, 2004; Redish, 2003; Sarwar, Bashir \& Alam, 2010; Simonson \& Maushak, 1996) that found a positive correlation between students' attitude and academic achievement. Matthew et al. (2011) concluded that the attitude toward mathematics was the predictor of the mathematic grade and Lipnevich, MacCann, Krumm, Burrus and Roberts (2011) results showed that attitudes toward mathematics explained between $25 \%$ and $32 \%$ of the variance in mathematics achievement among 8th graders in the samples from the USA and Belarus, consistent with the result of this research. A meta-analysis that investigated the relationship between the attitudes toward mathematics and mathematics achievement that consisted of 113 original studies showed a positive relationship between mathematics attitudes and mathematics performance, with a longitudinal model suggesting that mathematics attitudes actually constitute a causal factor in mathematics achievement (Ma \& Kishor, 1997). Marjoribanks (1987) found that for the middle-status family group boys' ability and affective attitudes were related to over $30 \%$ of the variation in mathematics scores; for the lower status families, these relations ranged from $15 \%$ to $24 \%$. Alrwais (2000) found that best predictor of mathematic achievement was the students' attitude toward mathematics learning. However, it cannot be concluded that positive attitude always results in high achievement in mathematics. For example, Kiely (1990, as cited in Atnafu, 2010) showed that on average, a small number of pupils who were not very good in mathematics obtained high scores in the attitude test. Addition- 
ally to these, Atnafu (2010) found a weak relationship between achievement in algebra and each of the five components of attitude such as confidence, usefulness, enjoyment, subject that is perceived as a male domain, and teacher expectations including the attitude toward algebra. The contribution of all components collectively that is confidence, usefulness, enjoyment, subject that is perceived as a male domain, and teacher expectations in algebra significantly affected the achievement of students in algebra. The contribution of confidence was significant on the achievement variable, but the other components, usefulness, enjoyment, subject perceived as a male domain, and teacher expectations were not significant predictors of the achievement variable. As discussed above, some researchers found the relationship between academic achievement and attitudes whereas some did not.

The necessity and importance of how the course was perceived by the students was one of the predictors of the academic achievement in this research indirectly related to and consistent with the research done by Simkins, Davis-Kean, \& Eccles, (2006) who found that math interest inventory for the $6^{\text {th }}$ grade students was a limited predictor of $10^{\text {th }}$ grade math students. Abu-Hilal (2000) found that students' perceptions of the importance of mathematics exerted a significant effect on achievement, which is consistent with result of this research.

Brophy (1985) emphasized that gender differences in academic achievement were declining and might eventually disappear. Murray-Harvey (1993) and Zeegers (2004) found that gender had no effect on academic achievement of college students, which is consistent with the findings of this research. Additionally, Hacket, Betz, Casas and Rocha-Singh (1992) observed few gender differences among college students in terms of academic achievement in their research, although women had higher high school GPAs, college GPAs, or a self-efficacy expectation, which is also aligned with the results of this research. Similarly to Brophy, Marsh (1989b) provided additional support for the diminishing gender differences in math and English achievement in a comparison of scores from several large, nationally representative studies of the U.S. high school students in the 1970s and the early 1980s (as cited in Marsh \& Yeung, 1998).

The research has some limitations. The variables measured as independent variables are not exactly independent of one another. Another issue is the generalizability of the findings, as this study conducted at a single institution, in one department and based on a course taught by one lecturer. Therefore, it may not be fully generalizable to other settings. Furthermore, the variables selected for this study may have omitted other significant predictors of student attainment that should be accounted for in predicting student achievement.

\section{Conclusion}

As it is stated in the results' section, the total study hours was the most significant variable that explained academic achievement of college students in SRMC. As Lahmers \& Zulauf (2000) stated following conventional wisdom, the time spent studying is expected to be positively related to academic performance. But the literature review revealed the association between academic achievements and studying time was inconsistent.

The study time-grade association literature has provided conflicting findings: some researchers have found a positive association, others a negative association, and yet others no association between the study time and grades. The research by Landrum, Turissi \& Brandel (2006) conducted among college students revealed that along with the study time A and B students had different adaptive strategies of studying than $C$ and $D$ students. Thus, it is not correct to explain studying time as an independent variable to predict academic achievement excluding studying strategies of students as it is stated in the Landrum's et al. study.

Beer \& Beer's (1992) research recorded over six years the number of hours and minutes they spent in each undergraduate and graduate class and the number of hours and minutes they spent outside of class reading, writing, and studying for the test and class. The results showed that the class hours correlated significantly and negatively with grades whereas there were no significant correlation found between home study hours $(M=38.2 ; S D=29.4, n=45)$ and grades $(M=3.9, S D=.3, n=45 ; r=0.09, p>0.05)$. Further, Beer and Beer found that both home study and grades were influenced by the number of course 
hours taken per semester. Taking more hours in demanding graduate courses tended to lower GPA.

Schuman's et al's (1985) research revealed a week but marginally significant association between GPA and hours studied hours. This relation was not strengthened by standardizing for credit hour load during the term, nor by taking into account the responses to a further question on whether recent amount of study time had changed as compared to earlier in the term. In addition, there was no other variable in Schuman's et al's survey that shows association with both hours studied and GPA that its inclusion in the prediction equation noticeably improved the relation.

Lahmers and Zulauf's (2000) research revealed that GPA increased only 0.025 points per additional study hour per week whereas the present research found that academic achievement in SRMC increased 0.388 point per additional study hour during the semester (the highest point was 100 whereas the least point was 0 ). For the average student in Lahmers and Zulauf's study, to rise his or her quarterly GPA by one letter grade, the estimated coefficient implies that study time would need to be increased by 26 hours. The research by Landrum et al. (2006) conducted with college students revealed that the examination of the means indicated that upper-division students studied more than twice of minutes per week (M $=529.5$ minutes, $\mathrm{SE}=54)$ than did lower division students $(\mathrm{M}=252.5 \mathrm{~min} ., \mathrm{SE}=17.4)$. Another result of this research was that means indicated students who received $A s(M=9.6, S E=0.9)$ reported studying significantly more often (twice) than students who received $\mathrm{Bs}(\mathrm{M}=3.8, \mathrm{SE}=0.8), \mathrm{Cs}(\mathrm{M}=4.5, \mathrm{SE}=0.3)$ or $\mathrm{Ds}(\mathrm{M}=4.5, \mathrm{SE}=0.2)$. There was also the main effect for time $(F(1,136)=11.36, \mathrm{p}<0.005, \mathrm{n} 2=0.08)$. Students studied more later $(M=441.4$ min., $S E=37)$ than earlier in the semester $(M=340.7$ min., SE $=26.2$. . Lahmers and Zulauf's (2000) research revealed that GPAs and class meeting times were factors that positively influenced the amount of study time; also, holding a job reduces study time, but only by 0.2 hours for each additional hour.

In this research, ATI was a non-significant variable in explaining academic achievement. one of the reasons may be that attitude may affect academic achievement in elementary, middle and high school, but not at the college level. The effect of attitude on achievement may decrease when the grade increases. This research was conducted with students attending the college of education and have high responsibility. Due to students' sense of responsibility they may not be affected by attitudes toward instructors during the course, especially in midterm and final exams. In addition, the CTM was another non-significant variable like ATI in this research. Due to taking the course from the same instructor, the students participated in this research were exposed to same teaching method. Therefore, non-significance of CTM in predicting academic achievement in SRMC could be supposed an expected result.

Finally to as a result of this study it is possible to suggest for college students in science courses to increase the academic achievement as following: 1) Students should study more. 2) Attitude of students towards course should be increased by lecturer during course. 3) Perception of the students about necessity and importance of the course should be increased by the lecturer during course.

\section{References}

Abu-Hilal, M. M. (2000). A structural model of attitudes toward school subjects, academic aspirations, and achievement. Educational Psychology, 20, 75-84.

Akbayır, K. (2003). Öğretmenlik mesleğine yönelmede ailenin ve branş seçiminde cinsiyetin rolü. [Families' role on teaching profession and gender role on subject]. $5^{\text {th }}$ National Congress of Science and Mathematics Education. Ankara: Middle East Technical University.

Allen, G. J., Lerner, W. M., \& Hinrichsen, J. J. (1972). Study behaviors and their relationships to test anxiety and academic performance. Psychological Reports, 30, 407-410.

Alrwais, A.M. (2000). The relationship among eighth-grade students' creativity, attitudes, school grade and their achievements in mathematics in Saudi Arabia. Doctoral Dissertation, Ohio University, Available at: wwwlib. umi.com/dissertations/results. Accessed November 25, 2012.

Aquino, L. B. (2011). Study habits and attitudes of freshmen students: Implications for academic intervention programs. Journal of Language Teaching and Research, 2 (5), 1116-1121.

Atnafu, M. (2010). Relation between tenth grade students' attitude and components of attitude in algebra with algebra achievement of Addis Ababa secondary schools, Ethiopia. International Journal for Mathematics Teaching and Learning. November. Available at: http://www.cimt.plymouth.ac.uk/journal/atnafu.pdf. Accessed November 25, 2012. 
Bachman, J. G., \& Schulenberg, J. (1993). How part-time work intensity relates to drug use, problem behavior, time use, and satisfaction among high school seniors: Are these consequences or merely correlates? Developmental Psychology, 29, 220-235.

Beauducel, A., \& Wittmann, W. W. (2005). Simulation study on fit indices in confirmatory factor analysis based on data with slightly distorted simple structure. Structural Equation Modelling: A Multidisciplinary Journal, 12 (1), $41-75$.

Beer, J., \& Beer, J. (1992). Classroom and home study times and grades while at college using a single subject design. Psychological Reports, 71, 233-234.

Benbow, C. P., \& Stanley, J. C. (1982). Intellectually talented boys and girls: Educational profiles. Gifted Child Quarterly, $26,82-88$

Bentler, P. M., \& Bonett, D. G. (1980). Significance tests and goodness of fit in the analysis of covariance structures. Psychological Bulletin, 88, 588-606.

Bloom, B. S. (1974). Time and learning. American Psychologist, 29, 682-688.

Britton, B. K., \& Tesser, A. (1991). Effects of time-management practices on college grades. Journal of Educational Psychology, 83, 405-410.

Capella, B. J., Wagner, M., \& Kusmierz, J. A. (1982). Relation of study habits and attitudes to academic performance. Psychological Reports, 50, 593-594.

Carey, N., \& Shevelson, R. (1988). Outcomes, achievement, participation, and attitudes. In R. J. Shavelson, L. M. McDonnell, and J. Oakes (Eds.) Indicators for monitoring mathematics and science education (pp. 147-191). Santa Monica, CA: Rand Corporation.

Cresswell, J.W. (2005). Educational research: Planning, conducting, and evaluating quantitative and qualitative research ( $2^{\text {nd }}$ Ed.). N. J.: Pearson.

Diaz, A. L. (2003). Personal, family, and academic factors affecting low achievement in secondary school. Electronic Journal of Research in Educational Psychology and Psycho Pedagogy, 1 (1), 43-66.

Fraenkel, J. R. \& Wallen, N. E. (2009). How to design and evaluate research in education (7th Ed.). PA: McGraw-Hill.

Fuligni, A. J. (1997). The academic achievement of adolescents from immigrant families: The roles of family background, Attitudes, and Behavior. Child Development, 68 (2), 351-363.

George, D., \& Mallery, M. P. (2001). Using SPSS for Windows step by step: A simple guide and reference. Boston, MA: Allyn \& Bacon.

Greenberger, E., \& Steinberg, L. (1986). When teenagers work: The psychological and social costs of adolescent employment. New York, NY: Basic Books.

Greenwald, A. G., \& Gillmore, G. M. (1997). No pain, no gain? The importance of measuring course workload in student ratings of instruction. Journal of Educational Psychology, 89 (4), 743-751.

Gustafson, J. E., \& Balke, G. (1993). General and specific abilities as predictors of school achievement. Multivariate Behavioural Research, 28 (4), 407-434.

Hackett, G., Betz, N. E., Casas, J. M., \& Rocha-Singh (1992). Gender, ethnicity, and social cognitive factors predicting the academic achievement of students in engineering. Journal of Counselling Psychology, 39 (4), 527-538.

Halpern, D. F. (1996). A process-oriented model of cognitive sex differences. Learning and Individual Differences, 8 , 3-24.

Hammer, D. (2000). Student resources for learning introductory physics. American Journal of Physics, 68 (1), 52-59.

Hinrichsen, J. J. (1972). Prediction of grade point average from estimated study behaviors. Psychological Reports, $31,974$.

House, J. D. (1996). Student expectancies and academic self-concept as predictors of science achievement. The Journal of Psychology, 130 (6), 679-681.

Hurk, M. M., Wolfhagen, I., Dolmans, D., \& Vleuten, C. (1999). The impact of student-generated issues on individual study time and academic achievement. Medical Education, 33, 808-814.

Hussain, A. (2006). Effect of guidance services on study attitudes, study habits and academic achievement of secondary school students. Bulletin of Education \& Research, 28 (1), 35-45.

Hyde, J. S., Fennema, E., \& Lamon, S. J. (1990). Gender differences in mathematics performance: A meta-analysis. Psychological Bulletin, 107, 139-153.

Ilgan, A., \& Kıranlı, S. (2008). Sınıf yönetimi ders başarısını yordayan değişkenler (Variables affecting the student's success of the classroom management course). Çağdaş Eğitim Dergisi, 33(359). 23-31.

Kaya, A., \& Büyükkasap, E. (2005). Fizik öğretmenliği programı öğrencilerinin prfilleri, öğretmenlik mesleğine yönelik tutum ve endişeleri: Erzurum örneği. [Physics student teachers' profiles, attitudes and anxiety toward teaching profession: An Erzurum sample]. Kastamonu Eğitim Dergisi, 13 (2), 367-380.

Kline, P. (2000). An easy guide to factor analysis. New York, NY: Routledge.

Kline, R. B. (2005). Principles and practice of structural equation modelling (2nd Ed.). New York: Guilford.

Kloosterman, P. (1991). Beliefs and achievement in seventh-grade mathematics. Focus on Learning Problems in Mathematics, 13, 3-15.

Lahmers, A. G., \& Zulauf, C. R. (2000). Factors associated with academic time use and academic performance of college students: A recursive approach. Journal of College Student Development, 41, 544-556. 
Landrum, R. E., Turrisi, R., \& Brandel, J. M. (2006). College students' study time: Course level, time of the semester, and grade earned. Psychological Reports, 98, 675-682.

Larson, R.W. (1983). Adolescents' daily experience with family and friends: Contrasting opportunity systems. Journal of Marriage and the Family, 45 (3), 739-750.

Lawson, A. E. (1983). Predicting science achievement: The role of development level, disembedding ability, mental capacity, prior knowledge, and beliefs. Journal of Research in Science Teaching. 20 (2), 117-129.

Leone, C. M., \& Richards, M. H. (1989). Classwork and homework in early adolescence: The ecology of achievement. Journal of Youth and Adolescence, 18, 531-548.

Lipnevich, A. A., MacCann, C., Krumm, S., Burrus, J., \& Roberts, R. D. (2011). Mathematics attitudes and mathematics outcomes of US and Belarusian middle school students. Journal of Educational Psychology, 103 (1), 105-118.

Lupart, J. L., Cannon, E., \& Tlefer, J. A. (2004). Gender differences in adolescent academic achievement, interests, values and life-role expectations. High Ability Studies, 15 (1), 25-42.

$\mathrm{Ma}, \mathrm{X}$., \& Xu, J. (2004). Determining the causal ordering between attitude toward mathematics and achievement in mathematics. American Journal of Education, 110 (3), 256-280.

Ma, X., \& Kishor, N. (1997). Assessing the relationship between attitude toward mathematics and achievement in mathematics: A meta-analysis. Journal of Research in Mathematics Education, 28 (1), 26-47.

Marjoribanks, K. (1987). Ability and attitude correlations of academic achievement: Family-group differences. Journal of Educational Psychology, 79 (2), 171-178.

Marsh, H. W., \& Yeung, A. S. (1998). Longitudinal structural equation models of academic self-concept and achievement: Gender differences in the development of math and English. American Educational Research Journal, 35 (4), 705-738.

Marsh, H. W., Hau, K. T., \& Wen, Z. (2004). In search of golden rules: Comment on hypothesis-testing approaches to setting cutoff values for fit indexes and dangers in overgeneralizing Hu and Bentler's (1999) findings. Structural Equation Modeling: A Multidisciplinary Journal, 11 (3), 320-341.

Matthews, J. S., Morrison, F. J., \& Ponitz, C. C. (2009). Early gender differences in self-regulations and academic achievement. Journal of Educational Psychology, 101 (3), 689-704.

Matthews, L. P., Haney, J. J., Worch, E. A., Underwood, E. M., Nurnberger-Haag, J. A., Scheuermann, A., \& Midden, R. W. (2011). Yes I can: The Contributions of motivation and attitudes on course performance among biology nonmajors. Journal of College Science Teaching, 40 (6), 86-95.

Michaels, J. W., \& Miethe, T. D. (1989). Academic effort and college grades. Social Forces, 68, 309-319.

Murray-Harvey, R. (1993). Identifying characteristic of successful tertiary students using path analysis. Australian Educational Researcher, 20, (3) 63-81.

Norwich, B., \& Ducan, J. (1990). Attitudes, subjective norm, perceived preventive factors, intentions and learning science: Testing a modified theory of reasoned action. British Journal of Educational Psychology, 60, 312-321.

Nowell, A., \& Hedges, L. V. (1998). Trends in gender differences in academic achievement from 1960 to 1994: An analysis of differences in mean, variance, and extreme. Sex Roles, 1 (2), 21-43.

Okpala P. N. (2001). Socio psychological factors, knowledge and understanding of mathematics as correlates of mathematics. Unpublished M.Ed Project. University of Benin, Benin.

Olivares, O. J. (2002). An analysis of the study time-grade association. Radical Pedagogy. 4 (1). Available at: http:// www.radicalpedagogy.org/Radical_Pedagogy/ An_Analysis_of_the_Study_Time-Grade_Association.html. Accessed March 24, 2013.

Paglin, M., \& Rufolo, A. M. (1990). Heterogeneous human capital, occupational choice, and male-female earnings differences. Journal of Labor Economics, 8, 123-144.

Papanastasiou, C., \& Papanastasiou, E. C. (2004). Major influences on attitudes toward science. Educational Research and Evaluation, 10 (3), 239-257.

Pintrich, P. R., \& Garcia, T. (1991). Student goal orientation and self-regulation in the college classroom. In M. L. Maehr \& P. R. Pintrich (Eds) Advances in Motivation and Achievement: Goals and Self-regulatory Processes (pp. 371-402). Greenwich, CT: JAI Press.

Plant, E. A., Ericsson, K. A., Hill, L., \& Asberg, K. (2004). Why study time does not predict grade point average across college students: Implications of deliberate practice for academic performance. Contemporary Educational Psychology, 30, 96-116.

Rau, W., \& Durand, A. (2000). The academic ethic and college grades: Does hard work help students to "make the grade?". Sociology of Education, 73, 19-38.

Raynolds, A. J., \&Walberg, H. J. (1992). A structural model of science achievement and attitude: An extension to high school. Journal of Educational Psychology, 84 (3), 371-382.

Redish, E. F. (2003). Teaching physics with physics suite. New York: John Wiley \& Sons.

Simonson, M., \& Maushak, N. (1996). Instructional technology and attitude change. In D. H. Jonassen (Ed.), Handbook of research for educational communications and technology. New York: Simon \& Schuster Macmillan.

Sarvar, M., Bashir, M., \& Alam, M. (2010). Study attitude and academic achievement at secondary level in Pakistan. Journal of College Teaching \& Learning, 7 (2), 55-60.

Schuman, H., Walsh, E., Olson, C., \& Etheridge, B. (1985). Effort and reward: The assumption that college grades are 
affected by quantity of study. Social Forces, 63, 945-966.

Stumpf, H. (1995). Gender differences in performance on tests of cognitive abilities: Experimental design issues and empirical results. Learning and Individual Differences, 7, 275-288.

Tabachnick, B. G., \& Fidell, L. S. (2001). Using multivariate statistics (4th Ed.). New York: Harper \& Row.

Tai, R. H. \& Sadler, P. M. (2001). Gender differences in introductory undergraduate physics performance: University physics versus college physics in the USA. International Journal of Science Education, 23 (10), 1017-1037.

Van Den Hurk, M. (2006). The relation between self-regulated strategies and individual study time, prepared participation and achievement in a problem-based curriculum. Active Learning in Higher Education, 7 (2), 155-169.

Vogt, P. (2005). Dictionary of statistic and methodology. London: Sage.

Worthington, R. L. \& Whittaker, T. A. (2006). Scale development research: a content analysis and recommendations for best practices. The Counselling Psychologist, 34 (6), 806-838.

Zeegers, P. (2004). Student learning in higher education: a path analysis of academic achievement in science. Higher Education Research \& Development, 23 (1), 35-56.

Zimmerman, B. J. (1994). Dimensions of academic self-regulation: A framework for education. In D. H. Schunk \& B. J. Zimmerman. (Eds), Regulation of learning and performance. Hillsdale, NJ: Lawrence Erlbaum.

Received: December 05, 2012

Accepted: May 05, 2013

Abdurrahman Ilgan Ph.D., Assistant Professor, Manisa Celal Bayar University, Faculty of Education Demirci, Manisa, Turkey.

E-mail: abdurrahmanilgan@gmail.com 